Pediat. Res. 3: 448-458 (1969)

Bilirubin

infants

glucose-6-phosphate jaundice

dehydrogenase

\title{
Incidence and Mechanism of Neonatal Jaundice Related to Glucose-6-Phosphate Dehydrogenase Deficiency
}

\author{
T.Valaes ${ }^{[42]}$, A. Karaklis, D. Stravrakakis, K. Bavela-Stravrakakis, A.Perakis \\ and S.A.DOXIADIS
}

The Queen Anna-Maria Institute of Child Health and the Aghia Sophia Children's Hospital, Athens, Greece

Extract

In three population surveys in Greece, the incidence of glucose-6-phosphate dehydrogenase (G-6-PD) deficiency and neonatal jaundice was examined in randomly selected male newborns. The incidence rate of G-6-PD deficiency was $2.92 \%$ in the Alexandra survey (population of Athens and southern Greece), $4.93 \%$ in the Lesbos survey and $12.5 \%$ in the Rhodes survey. In all surveys, severe jaundice without blood group incompatibility or low birth weight appeared much more frequently in G-6-PDdeficient than in normal newborns, but there were striking differences. In Lesbos, severe jaundice was found much more frequently in both G-6-PD-deficient and normal groups than in comparable groups in the other two surveys. Similarly, at 4 days of age, values for serum bilirubin in control groups were $9.43 \pm 4.39 \mathrm{mg} / 100 \mathrm{ml}$ in Lesbos and $7.88 \pm 4.8 \mathrm{mg} / 100 \mathrm{ml}$ in Rhodes $(p<0.05)$. These differences indicate that in Lesbos, an unknown icterogenic factor alone increases the incidence of neonatal hyperbilirubinemia and, in conjunction with G-6-PD deficiency, causes severe neonatal jaundice (serum bilirubin values higher than $16 \mathrm{mg} / 100 \mathrm{ml}$ ) in $43 \%$ of G-6-PD deficient infants.

In the Rhodes survey, values for hemoglobin and serum bilirubin and reticulocyte count in the G-6-PD-deficient group were compared with values in the cord blood and in samples of blood drawn on the 4th day of life from the control group. The G-6-PD-deficient group had lower hemoglobin values and higher serum bilirubin values than the control group. The mean values $(\mathrm{g} / 100 \mathrm{ml})$ for hemoglobin in cord blood were $14.42 \pm 1.24$ and $15.36 \pm 1.36$ in the G-6-PD-deficient and control groups, respectively. In samples obtained at 4 days of age, the values were $15.6 \pm 1.34$ and $16.65 \pm 1.37$, respectively, in the two groups. The mean values $(\mathrm{mg} / 100 \mathrm{ml}$ ) for serum bilirubin in cord blood were $1.98 \pm 0.64$ and $1.68 \pm 0.42$, respectively, in the two groups. At 4 days of age, the values were $9.86 \pm 6.6$ and $7.88 \pm 4.8$, respectively. These results indicate a diminished life span of G-6-PD-deficient erythrocytes in the fetal and neonatal period.

\section{Speculation}

This study demonstrates the existence in some newborn populations of an icterogenic factor unrelated to blood group incompatibility or G-6-PD deficiency.

Further studies are needed to determine the hemolytic or hepatic nature of this factor and whether this factor interacts with $\mathrm{ABO}$ incompatibility or prematurity. In this work, the relation of this factor to G-6-PD deficiency has been studied. 


\section{Introduction}

In 1955, we reported that in a large number of cases of severe jaundice in Greek newborns, blood group incompatibility was absent [26]. This finding prompted a series of systematic studies in search for new causes of neonatal jaundice. As a result of those studies, it was shown in 1960, that glucose-6-phosphate dehydrogenase (G-6-PD) deficiency was causally related to the development of severe jaundice and kernicterus in some newborns [10]. At the same time, isolated reports of cases of severe jaundice associated with this enzyme deficiency appeared in Italy [24], Singapore [28] and Malay [36]. The etiological relation of severe jaundice to G-6-PD deficiency was firmly established when the incidence of this enzyme defect was reported to be approximately 20 times higher in a group of infants with unexplained severe neonatal jaundice than it was in control groups of normal infants or infants with severe jaundice of known etiology [8,9]. As anticipated [31], this discovery of a red cell enzyme defect in severe neonatal jaundice opened a new chapter in the etiology of neonatal jaundice that includes a number of red cell enzymopathies [32].

A number of studies have demonstrated the role of G-6-PD in maintaining the integrity of the red cell under oxidative stress $[2,6,17,30,35]$. Thus, an assumption could be made that an exogenous hemolytic factor was necessary for the development of severe jaundice in the G-6-PD-deficient babies. When such a factor could not be found, an unidentified one was invoked $[5,28,36]$, but the possibility of the latter factor appeared unlikely for the cases described in Greece and Italy.

In 1962, incidence of severe jaundice was reported much higher in siblings of newborns with severe jaundice arising from G-6-PD deficiency than it was in the general population of G-6-PD-deficient neonates [13]. This finding led to the hypothesis that a second, independently transmitted hereditary factor was necessary for the development of severe jaundice in G-6-PDdeficient neonates. PAnizon [24] had previously reported this familial incidence in isolated cases.

Population group studies on the relation of G-6-PD deficiency to neonatal jaundice showed that in the American Negro [37, 39] and in Israel [29], this manifestation of G-6-PD deficiency was practically absent. In Greece and in Turkey [27], in Sardinia [24, 25], and among the Malayans and Chinese in Singapore $[5,28,36]$, neonatal jaundice was a frequent manifestation of G-6-PD deficiency. These geographical and racial differences suggested that either the elusive exogenous factor was present only in some areas or that an additional genetic factor was present only in some races.
The field surveys used in the present study were designed to obtain epidemiological data to investigate the problem of the pathogenesis of jaundice caused by G-6-PD deficiency. The island of Lesbos was chosen because incidence of severe hyperbilirubinemia without incompatibility was known to be high. Rhodes was selected for the opposite reason. Since G-6-PD deficiency had been reported to be present in high frequency in that region [13], severe jaundice was expected to occur rarely.

The results of these two surveys will be compared with data from a previous survey covering the general population of Greece.

\section{Material}

The Alexandra survey included 786 randomly selected male newborns studied at the State and University Alexandra Maternity Hospital in Athens [13]. This group can be considered representative of the population of Southern Greece and will be used for comparison with the groups in the other two surveys.

The Lesbos survey was conducted during two study periods. The first period (September 1962-August 1963) included 634 male newborns who comprised $97.9 \%$ of all males born to inhabitants of a specific geographical area of the island [12]. The second period (November 1963-August 1964) included consecutive male births in the general hospital and private nursing clinics in the town of Mytilene. Data obtained during both periods are combined.

The Rhodes survey included all male newborns delivered in the general hospital and private clinics of the town of Rhodes during 1966.

In both Lesbos and Rhodes, most infants were breast fed exclusively during the 1 st week of life.

\section{Methods}

In all surveys, the brilliant cresyl blue (BCB) decolorization test described by Motulsky and CAMpbellKRAUT [21] was used for determining G-6-PD. All samples were tested at least twice: the first time, locally, in Lesbos or in Rhodes, and the second time, in our central laboratory. All samples found to be deficient in G-6-PD were tested a third time. In most of the G-6-PD-deficient infants from Lesbos, the enzyme activity was estimated quantitatively. Since, in the Lesbos survey no discrepancy was found between the $B C B$ test and the quantitative results, this step was omitted in the Rhodes survey.

All babies were observed daily, if possible, and the presence and degree of jaundice was ascertained by 
visual examination. In infants presenting more than moderate jaundice, serum bilirubin was measured. If the clinical condition of the children warranted further study, measurements were repeated. In the Rhodes survey, the blood groups of all mothers and babies were determined. In addition, serum bilirubin was measured on the 4th day of life in most infants with G-6-PD deficiency.

Samples from cord blood and blood obtained on the 4th day of life were measured for levels of serum bilirubin. Analyses were carried out in the central laboratory [19] in accordance with recommendations for a uniform bilirubin standard [7]. The values obtained were regularly checked by using 'Versatol Pediatric' ${ }^{\circledR}$ for comparison. Standard methods were used for all other laboratory studies. Student's t test was used for estimation of probability values.

\section{Results}

Incidence of Severe Neonatal Jaundice in the Three Surveys

The incidence of G-6-PD deficiency, as well as the incidence of severe jaundice in the G-6-PD normal and in the deficient male newborns, is shown in table $\mathrm{I}$. The number of infants who required an exchange transfusion, which was usually performed when serum bilirubin reached a level $>25 \mathrm{mg} / 100 \mathrm{ml}$, or who developed kernicterus is also shown.
The incidence of severe jaundice was much higher in the G-6-PD-deficient neonates than in the corresponding group of normal infants. In the Alexandra survey, the differences did not reach levels of statistical significance $(0.1<\mathrm{p}<0.02)$, but in the other two surveys, the differences were highly significant $(p<0.001)$.

In the three surveys, there were significant differences in the incidence of severe jaundice in both normal infants and those deficient in G-6-PD activity; moreover, the differences were in the same direction and were approximately of the same magnitude for both groups. In Rhodes and in Lesbos, the incidence of severe jaundice in the two groups was 2-3 times higher and 10 times higher, respectively, than that in the corresponding groups of the Alexandra survey.

The results of the study of the cases of severe jaundice are shown in table II. Data were analyzed according to the presence or absence of fetomaternal blood group incompatibility or low birth weight $(<2,500 \mathrm{~g})$.

Severe jaundice caused by Rhesus isoimmunization was rare. There were only two cases in the 2,599 male newborns of the three surveys.

There were striking differences in the severe jaundice that developed in infants who had no blood group incompatibility and who were not of low birth weight. In the Alexandra survey, one such case occurred in every 400 births of G-6-PD normal males; one occurred in every 100 births in the Rhodes survey and one in every 15 births in the Lesbos survey. Exchange trans-

Table I. Incidence of G-6-PD deficiency and severe neonatal jaundice in three populations of randomly selected male newborns

\begin{tabular}{lccccc}
\hline Survey & No. of patients & G-6-PD activity & No. in group & $\begin{array}{c}\text { No. with severe } \\
\text { jaundice }\end{array}$ & $\begin{array}{c}\text { No. with } \\
\text { exchange } \\
\text { transfusion or } \\
\text { kernicterus }\end{array}$ \\
\cline { 3 - 5 } & & Normal & 763 & $(\%)$ & \\
\hline Alexandra & 786 & & 8 & 1 \\
& & Deficient & 23 & $(1.04)$ & $(0.13)$ \\
& & Normal & $(2.92)$ & $(4.34)$ & - \\
Lesbos & 1317 & Deficient & 652 & 137 & 22 \\
& & & $(4.93)$ & $(43.0)$ & $(12.3)$ \\
& & Normal & 434 & 10 & - \\
Rhodes & 496 & Deficient & 62 & $(2.3)$ & 7 \\
& & & $(12.5)$ & $(11.29)$ & $(4.8)$ \\
\hline
\end{tabular}

${ }^{\mathrm{x}}$ Marked jaundice by visual estimation and bilirubin levels in serum, value $\geqq 16 \mathrm{mg} / 100 \mathrm{ml}$. 
fusion was necessary for infants with normal G-6-PD activity and without incompatibility in the Lesbos survey only. In this survey, both the frequency and severity of jaundice resulting from $\mathrm{ABO}$ incompatibility and prematurity was higher than that in the other two surveys, although the difference was not as striking and did not reach the levels of statistical significance that occurred in the group without incompatibility.

Six cases of kernicterus occurred in G-6-PD-deficient infants with no incompatibility. Three infants were in Lesbos and three were in Rhodes. Prevention of kernicterus failed because the babies could not be brought to Athens for exchange transfusion.

\section{Laboratory Data on the Cases of Severe Faundice} in the Lesbos Survey

Laboratory and clinical data on the infants with G-6-PD deficiency and of those with normal G-6-PD activity and no incompatibility are compared in table III; also, data on the group with ABO incompatibility, a group with known hemolysis, are presented for comparison.

Maximal or preexchange transfusion values for serum bilirubin and minimal or preexchange values for hemoglobin were obtained in infants classified according to three etiological groups: $\mathrm{ABO}$ incompatibility; G-6-PD activity normal and no incompatibility; and G-6-PD activity deficient and no incompatibility (fig. 1). The rapid rise in the level of serum bilirubin and/or the low hemoglobin values in some infants in each group clearly demonstrated a hemolytic process. In the majority of the infants, however, neither of these criteria was present and it is unclear whether the predominant factor in the mechanism of jaundice is hemolysis or deficient excretion of bilirubin.

In the group about which we have less information, those with normal G-6-PD activity and no incompatibility, jaundice appeared in 11 infants within the first $48 \mathrm{~h}$ after birth; in the remaining patients, jaundice appeared within $96 \mathrm{~h}$. None had a high reticulocyte count, none had more than an occasional red cell with Heinz bodies, and none had pyknocytosis. Eleven infants had hemoglobin values below $15 \mathrm{~g} / 100 \mathrm{ml}$, and nine had values of $20 \mathrm{~g} / 100 \mathrm{ml}$ or more (fig. 1). Hemoglobin values and reticulocyte counts of this group are compared with those of a control group (randomly selected male full-term infants with normal G-6-PD activity and with no incompatibility) to assess the importance of hemolysis in the development of jaundice (table III). The difference in the mean hemoglobin values of the two groups was statistically significant $(p<0.05)$. However, in the severely jaundiced infants, those who required exchange transfusion had a mean hemoglobin value of $18.3 \pm 2.21 \mathrm{~g} / 100 \mathrm{ml}$, while those who required no treatment had a mean value of $16.8 \pm$ $2.14 \mathrm{~g} / 100 \mathrm{ml}(\mathrm{p}<0.05)$. These results suggest that the rate of hemolysis was not the main factor influencing the degree of hyperbilirubinemia.

In the group of G-6-PD-deficient infants without incompatibility, jaundice appeared on the 1st day of life in only four infants (fig. 1). In the remaining in-

Table II. Analysis of the cases of severe neonatal jaundice ${ }^{1}$

\begin{tabular}{|c|c|c|c|c|c|c|c|}
\hline Survey & $\begin{array}{c}\text { No. of } \\
\text { patients }\end{array}$ & G-6-PD activity & $\begin{array}{l}\text { Rhesus } \\
\text { incom- } \\
\text { patibility }\end{array}$ & $\begin{array}{c}\mathrm{ABO} \\
\text { incom- } \\
\text { patibility }{ }^{2}\end{array}$ & $\begin{array}{c}\text { Low birth } \\
\text { wt }\end{array}$ & $\begin{array}{l}\text { No in- } \\
\text { com- } \\
\text { patibility }\end{array}$ & $\begin{array}{l}\text { No. with } \\
\text { severe } \\
\text { jaundice }\end{array}$ \\
\hline \multirow[t]{2}{*}{ Alexandra } & 763 & Normal & $1(1)^{3}$ & 3 & 2 & 2 & 8 \\
\hline & 23 & Deficient & - & - & - & 1 & 1 \\
\hline \multirow[t]{3}{*}{ Lesbos } & 1252 & Normal & 1 & $30(7)$ & $6(2)$ & $100^{4}(12)$ & 137 \\
\hline & 65 & Deficient & - & 3 & - & $25(8)$ & 28 \\
\hline & 434 & Normal & - & $4^{5}$ & 1 & 5 & 10 \\
\hline Rhodes & 62 & Deficient & - & 2 & 1 & $4(3)$ & 7 \\
\hline
\end{tabular}

${ }^{1}$ Levels of bilirubin in serum $\geqq 16 \mathrm{mg} / 100 \mathrm{ml}$.

${ }^{2}$ Includes all group $\mathrm{A}$ or $\mathrm{B}$ infants of group $\mathrm{O}$ mothers irrespective of clinical or serological evidence of $\mathrm{ABO}$ hemolytic disease.

${ }^{3}$ Number of infants treated by exchange transfusion or with kernicterus appear in parentheses.

${ }^{4}$ Includes 18 infants in whom the blood group of the mother was not available but all evidence identifies them as belonging to this group.

${ }^{5}$ Includes two low birth weight infants. 


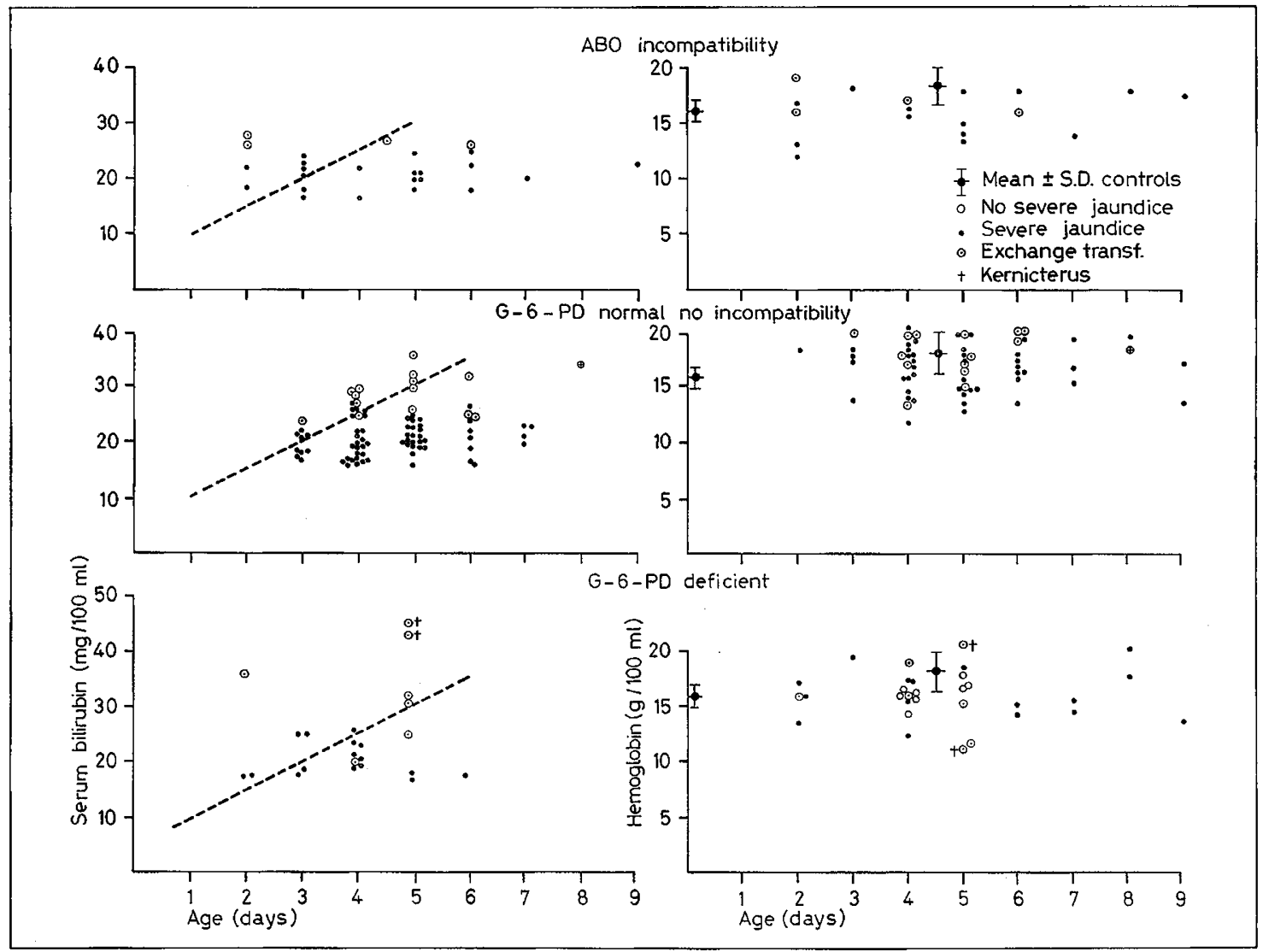

Fig. 1. Lesbos survey: hemoglobin and maximum serum bilirubin values in three etiological groups of severe neonatal jaundice. The interrupted line indicates the expected rate of maximal serum bilirubin rise under the theoretical conditions of complete blockage of bilirubin elimination but normal rate of hemolysis.

Table III. Lesbos survey: comparison of hemoglobin and reticulocyte values ${ }^{1}$

\begin{tabular}{lcccc}
\hline & \multicolumn{4}{c}{ Severe jaundice } \\
\cline { 2 - 4 } & Controls & $\begin{array}{c}\text { G-6-PD normal, } \\
\text { no incompatibility }\end{array}$ & G-6-PD deficient & ABO incompatibility \\
\hline Hemoglobin, $^{2}$ & $(17)^{3}$ & $(60)$ & $(22)$ & $(18)$ \\
g/100 ml & $18.23 \pm 1.84$ & $17.14 \pm 2.2$ & $16.05 \pm 2.63$ & $16.01 \pm 3.26$ \\
Reticulocytes, ${ }^{1} \%$ & $(48)$ & $(59)$ & $(23)$ & $(19)$ \\
& $1.63 \pm 1.00$ & $1.67 \pm 0.85$ & $1.97 \pm 1.2$ & $4.04 \pm 5$ \\
& $(0.8-6.4)$ & $(0.4-3.6)$ & $(0.4-4.0)$ & $(0.7-20.4)$ \\
\hline
\end{tabular}

1 Values given in mean $\pm \mathrm{SD}$ and for reticulocytes, range.

2 The age at sampling is shown in fig. 1 . For the controls it was the 4 th or 5 th day of life.

${ }^{3}$ Number in parentheses indicates number of cases. 
fants, onset of jaundice varied from the 2 nd to the 4 th day. Although seven infants in this group had hemoglobin values under $15 \mathrm{~g} / 100 \mathrm{ml}$, a larger number of infants were found to have high values; thus, the leve] of hemoglobin appeared to be a poor indicator of the mechanism of jaundice. The mean hemoglobin value of the infants with severe jaundice was $16.05 \pm 2.63 \mathrm{~g} /$ $100 \mathrm{ml}$, a value significantly lower $(\mathrm{p}<0.01)$ than that of controls, indicating the presence of hemolysis (table III). The group with G-6-PD deficiency also had a higher mean reticulocyte count, compared with that of the control group, but the difference was not statistically significant $(0.1<\mathrm{p}<0.2)$. Pyknocytosis and red cells with Heinz bodies were not observed in any infant in this group.

\section{Laboratory Data on the Rhodes Survey}

Values for hemoglobin, serum bilirubin, and reticulocyte count in cord blood and in venous blood drawn on the 4th day were determined in two groups of infants (table IV). The control group included consecutive males of birth weight over $2,500 \mathrm{~g}$, with normal G-6-PD activity and with no fetomaternal blood group incompatibility. In the G-6-PD-deficient infants, those with $\mathrm{ABO}$ incompatibility and those with low birth weights were excluded.

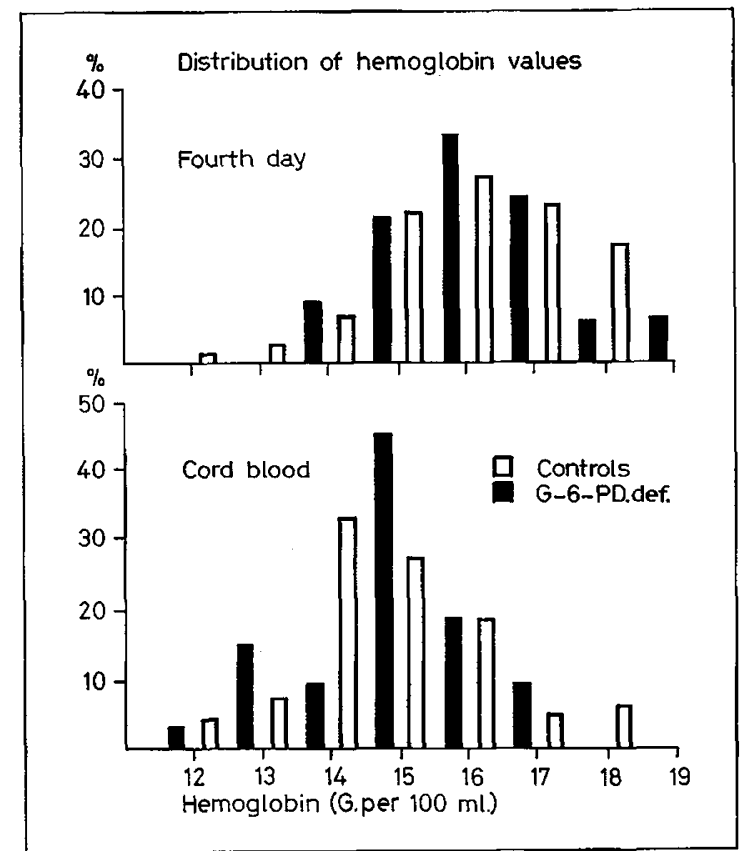

Fig. 2. Rhodes survey: distribution of cord blood and 4th-day hemoglobin values in two groups of newborns.

Table IV. Comparison of values for hemoglobin, reticulocyte count and serum bilirubin

\begin{tabular}{|c|c|c|c|c|}
\hline & & \multicolumn{2}{|c|}{ Rhodes survey ${ }^{1}$} & \multirow{2}{*}{$\frac{\text { Lesbos survey }}{\text { Controls }}$} \\
\hline & & Controls & G-6-PD deficient & \\
\hline $\begin{array}{l}\text { Hemoglobin, } \\
\mathrm{g} / 100 \mathrm{ml}\end{array}$ & $\begin{array}{l}\text { Cord blood } \\
\text { Venous blood, 4th day }\end{array}$ & $\begin{array}{c}(70)^{2} \\
15.36 \pm 1.36 \\
(70) \\
16.65 \pm 1.37\end{array}$ & $\begin{array}{c}(33) \\
14.42 \pm 1.24 \\
(33) \\
15.60 \pm 1.34\end{array}$ & $\begin{array}{c}(54) \\
16.28 \pm 0.74 \\
(17) \\
18.23 \pm 1.84\end{array}$ \\
\hline $\begin{array}{l}\text { Reticulocytes, } \\
\%\end{array}$ & $\begin{array}{l}\text { Cord blood } \\
\text { Venous blood, 4th day }\end{array}$ & $\begin{array}{c}(57) \\
3.25 \pm 1.06 \\
(1.0-6.51) \\
(56) \\
1.68 \pm 0.93 \\
(0.4-6.9)\end{array}$ & $\begin{array}{c}(38) \\
3.62 \pm 1.15 \\
(0.5-8.0) \\
(37) \\
2.1 \pm 0.96 \\
(0.5-4.7)\end{array}$ & $\begin{array}{c}(69) \\
3.2 \pm 1.23 \\
(1.0-6.4) \\
(48) \\
1.63 \pm 1.0 \\
(0.8-6.4)\end{array}$ \\
\hline $\begin{array}{l}\text { Serum bilirubin, } \\
\mathrm{mg} / 100 \mathrm{ml}\end{array}$ & $\begin{array}{l}\text { Cord blood } \\
\text { Venous blood, 4th day }\end{array}$ & $\begin{array}{c}(84) \\
1.68 \pm 0.42 \\
(86) \\
7.88 \pm 4.8\end{array}$ & $\begin{array}{c}(47) \\
1.98 \pm 0.64 \\
(39) \\
9.86 \pm 6.6\end{array}$ & $\begin{array}{c}(56) \\
1.91 \pm 0.75 \\
(60) \\
9.43 \pm 4.39\end{array}$ \\
\hline
\end{tabular}

${ }^{1}$ In the Rhodes survey the comparison between the control and G-6-PD-deficient groups gives the following results: hemoglobin: cord blood $\mathrm{p}<0.01$; 4 th day $\mathrm{p}<0.05$; reticulocytes: cord blood $0.09<\mathrm{p}<0.10$; 4 th day $0.08<\mathrm{p}<0.09$; serum bilirubin: cord blood $\mathrm{p}<0.005 ; 4$ th day $0.09<\mathrm{p}<0.10$.

${ }^{2}$ Number in parentheses indicates number of patients. Values given in mean $\pm S D$ and where indicated, range. 
Table V. Relation of severe jaundice from G-6-PD deficiency and frequency of gene and incidence of jaundice within the G-6-PD-deficient group in three populations

\begin{tabular}{|c|c|c|c|c|c|c|}
\hline \multirow[t]{2}{*}{ Survey } & \multicolumn{2}{|c|}{$\begin{array}{c}\text { Incidence of severe jaundice } \\
\text { in G-6-PD deficiency }\end{array}$} & \multicolumn{2}{|c|}{$\begin{array}{l}\text { Incidence of G-6-PD } \\
\text { deficiency }\end{array}$} & \multicolumn{2}{|c|}{$\begin{array}{c}\text { Relation of severe jaundice } \\
\text { from G-6-PD to all cases } \\
\text { of severe jaundice }\end{array}$} \\
\hline & $\%$ & factor $^{1}$ & $\%$ & factor & $\%$ & factor \\
\hline Alexandra & 4.34 & 1 & 2.92 & 1 & 11 & 1 \\
\hline Lesbos & 43.0 & 10 & 4.93 & 1.7 & 17 & 1.6 \\
\hline Rhodes & 11.29 & 2.6 & 12.5 & 4.2 & 41 & 3.7 \\
\hline
\end{tabular}

${ }^{1}$ Factor $=$ number by which the value for the Alexandra survey should be multiplied to obtain the corresponding values of the other surveys.

The G-6-PD-deficient infants, compared with the controls, showed lower hemoglobin values and higher reticulocyte counts and serum bilirubin values in both the cord blood and the 4th-day samples. The differences in hemoglobin and serum bilirubin in cord blood were statistically significant.

If the group of G-6-PD-deficient infants with no incompatibility or low birth weight is divided according to the serum bilirubin value on the 4th day into two groups, those below (24 cases) and those above (9 cases) $12 \mathrm{mg} / 100 \mathrm{ml}$, the latter group had significantly lower 4th-day hemoglobin values, indicating increased hemolysis.

In the two groups, the distribution of hemoglobin values in cord blood and 4th-day blood is shown in fig. 2. In comparison with the control group, the G-6PD-deficient infants showed a general shift of the distribution curve toward lower values.

Additional Differences in the Control Groups of Lesbos and Rhodes

In these surveys, there were significant differences in the incidence of severe neonatal jaundice (tables I and II). There were also differences in the control groups of the two surveys (table IV). The values for hemoglobin in cord blood were higher in infants in the Lesbos survey, $16.28 \pm 0.74 \mathrm{~g} / 100 \mathrm{ml}$, than they were in infants in the Rhodes survey, $15.36 \pm 1.36 \mathrm{~g} / 100 \mathrm{ml}$ $(p<0.01)$. Similarly, higher values of hemoglobin were found in the infants in the Lesbos survey on the 4th-5th day of life compared with values in infants in the Rhodes survey, $18.23 \pm 1.84$ versus $16.65 \pm 1.37$ $\mathrm{g} / 100 \mathrm{ml}(\mathrm{p}<0.001)$. No differences were observed in the reticulocyte counts. Higher values for serum bilirubin were found in the Lesbos group both in the cord blood samples, $1.9 \pm 0.75$ versus $1.68 \pm 0.42 \mathrm{mg} / 100 \mathrm{ml}$, and in the 4 th-day samples, $9.43 \pm 4.34$ versus $7.88 \pm$ $4.80 \mathrm{mg} / 100 \mathrm{ml}(\mathrm{p}<0.05)$.

\section{Discussion}

This study confirms the importance of G-6-PD deficiency as a cause of severe neonatal jaundice and kernicterus in Greek newborns. In the three surveys, the severe jaundice that occurred without incompatibility or low birth weight was most frequent and most severe among G-6-PD-deficient infants.

The association of G-6-PD deficiency and neonatal jaundice has been firmly established and the exact frequencies of severe jaundice have been recorded in large populations of randomly selected male newborns. Since most of the infants were delivered in hospitals or in private clinics and the drugs used prior to and during labor were recorded, it is unlikely that development of severe jaundice in the G-6-PD-deficient infants was the result of the presence of any known hemolytic agent.

Other similar surveys, of Sardinian [24, 25], Chinese $[5,20,38]$, and Turkish [27] newborns as well as of Thai and Chinese newborns of the Bangkok region [14], have shown that severe jaundice is associated with G-6-PD deficiency. Surveys of newborns in Northern Thailand [15], in Israel [29], and in American Negroes $[22,37,39]$ have failed to demonstrate this association.

From these and our own surveys it is evident that the risk of G-6-PD-deficient infants developing severe jaundice varies widely throughout the world.

It is assumed that excessive hemolysis is the basis for the development of severe jaundice in these infants. In the present study, there was unequivocal evidence of hemolysis in many of the infants. Also, in the G-6-PD-deficient infants in Rhodes, those with serum bilirubin levels above $12 \mathrm{mg} / 100 \mathrm{ml}$ at 4 days of age had significantly lower hemoglobin levels than did those whose serum bilirubin levels were below this value. In individual cases, however, there was not always a correlation between the degree of hyperbilirubinemia and anemia [11]. 
This finding is shown by the two cases of kernicterus illustrated in fig. 1 . Both had similar levels of serum bilirubin, yet hemoglobin values were 11.5 and $20 \mathrm{~g} /$ $100 \mathrm{ml}$, respectively. Nevertheless, the rate of rise of serum bilirubin leaves no doubt that even in the latter case excessive hemolysis was present.

In comparison with normals, the G-6-PD-deficient infants showed lower values for hemoglobin and higher values for serum bilirubin and reticulocyte counts even in cord blood. The differences in the hemoglobin values seem to have been due to a shift towards lower values of the whole group and not to a few values departing from the normal distribution. These findings suggest that an increased rate of hemolysis existed prenatally in the G-6-PD-deficient infants. This increased rate was sufficient to lower the hemoglobin and raise the serum bilirubin values of the whole group, but not enough to produce a significant reticulocyte response or frank anemia. Brown and Boon [5] reported similar findings in G-6-PD-deficient infants mainly of Chinese origin. The appearance of jaundice in the first $24 \mathrm{~h}$ of life in some of the G-6-PD-deficient infants also points to a very early onset of hemolysis. Lu et al. [20] reached the same conclusion from the finding that the G-6-PD-deficient group had higher mean serum bilirubin values even on the 1st day of life. The lower hemoglobin values on the 4th day are also evidence for the presence of increased hemolysis.

In the Rhodes survey, serum bilirubin values of the G-6-PD-deficient infants at 4 days of age were higher than values in the normals, but the differences were not statistically significant. Similar studies among Chinese infants $[5,20]$ showed high serum bilirubin values in G-6-PD-deficient infants. This was true, but to a lesser degree, in the study of PANIzon and MELA [25]. It is evident that the variation in bilirubin values existing in any group of neonates prevents the differences of the mean values from reaching statistically significant levels in some of the groups studied so far. However, the trend toward higher values in the G-6PD-deficient infants cannot be ignored and indicates that G-6-PD deficiency increases the level of neonatal hyperbilirubinemia, at least among Greek, Chinese, and Sardinian infants.

The mechanism of increased hemolysis should be considered. Erythrocytes deficient in G-6-PD activity have been found to have a shortened life span in the absence of any exogenous hemolytic agent in adults [3]. This enhanced hemolysis is usually fully compensated. It is quite possible that a similar shortening of the red cell life span cannot be fully compensated in fetal life, and thus hemoglobin values are slightly lower in cord blood. Moreover, the shorter life span of the G-6-PDdeficient red cell during the fetal and neonatal period may be even greater than in adults. Indeed, shortened life span of the red cells in normal full-term and even more in premature infants has been described [18, 34] and has lately been attributed to a number of transient metabolic defects of the red cells [16, 23].

At the present time, it is not known whether the group of G-6-PD-deficient infants was homogeneous and those infants exhibiting extreme hyperbilirubinemia were simply within the upper tail of a normal distribution curve. We suspect that this small group with very high bilirubin levels was different, and it is in this group that the second genetic factor, suspected from the family histories [13], may have been operating.

If increased hemolysis in the whole group of G-6-PDdeficient infants is accepted, the differences in the frequency of severe jaundice observed in several ethnic groups and in our surveys, even between groups of the same ethnic origin, remains to be explained. In this respect, one observation should be helpful. In Lesbos infants as well as in Chinese [4, 20] and in Malayan infants [4], neonatal hyperbilirubinemia was accentuated even among the normal infants. In three widely separated locations, Formosa, Singapore and Lesbos, the same phenomenon has been observed. In these areas, G-6-PD normal newborns generally had higher levels of serum bilirubin during the 1st week of life and even reached dangerous levels, necessitating exchange transfusion. In the same areas, the risk of severe jaundice among G-6-PD-deficient infants was found to be very high. In these groups a factor exists which appears capable of producing hyperbilirubinemia in newborns. In combination with G-6-PD deficiency, this effect is accentuated.

Thus, as we have previously postulated [33], there appears to be a relation between the general pattern of hyperbilirubinemia in the population and the frequency of severe jaundice in G-6-PD-deficient newborns. This relation becomes apparent by considering our data in another way. In the three surveys, the relation between the incidence of severe jaundice among the G-6-PD-deficient newborns, the incidence of the G-6-PD deficiency itself, and the percentage of cases of severe jaundice from G-6-PD deficiency was examined (table V). From this table, it can be seen that the last variable closely parallels the frequency of the G-6-PD deficiency gene in the population, but not the frequency of severe jaundice occurring within the group of G-6-PD-deficient newborns. Jaundice in both normal newborns and in those deficient in G-6PD was conditioned by a common factor, and a proportional rise was observed in both groups. The relative importance of G-6-PD deficiency as a cause of neonatal jaundice was determined by the frequency of the G-6-PD deficiency gene.

BRown and Boon $[4,5]$, in an attempt to explain the higher bilirubin levels of Chinese and other Asian 
groups in comparison with levels in Europeans living in Singapore, considered genetic differences that might affect bilirubin metabolism or that herbs used in traditional Ghinese medicine might have a hemolytic effect. The nature of the icterogenic factor affecting the population of Lesbos is uncertain. The results of analysis of the group with severe jaundice without incompatibility or G-6-PD deficiency are contradictory. The group as a whole had lower hemoglobin values than did the control group. Furthermore, the rapid rise in serum bilirubin and the appearance in some infants of jaundice during the first $24 \mathrm{~h}$ of life clearly indicate excessive hemolysis. In contrast, those infants with the highest serum bilirubin levels had significantly higher hemoglobin values than the rest, indicating that increased hemolysis was not necessarily the only factor.

Similarly, judged from the hemoglobin values, the difference between the incidence of severe jaundice in the G-6-PD-deficient group in Rhodes and that in Lesbos cannot be attributed solely to the higher rates of hemolysis in the Lesbos group.

The present epidemiological studies, together with similar studies in Formosa and Singapore, have uncovered a previously unsuspected problem in the field of neonatal jaundice. Under the striking differences in the incidence of severe neonatal jaundice among the G-6-PD-deficient infants lay a more subtle and more intriguing difference in the degree of unspecified hyperbilirubinemia among populations. Further study of this difference will greatly help in understanding the field of neonatal jaundice.

\section{Summary}

The incidence of glucose-6-phosphate dehydrogenase deficiency and severe jaundice was studied in the populations of the islands of Lesbos and Rhodes. The results of these two surveys are compared with those of a previous survey, covering the general population of Greece.

In all surveys, the incidence of severe jaundice was significantly higher in G-6-PD-deficient newborns. In the Lesbos survey, neonatal jaundice was much more frequent and more severe in both G-6-PD-deficient and in normal newborns than it was in these groups of infants in the other two surveys. The difference was due mainly to full-term newborns who developed severe jaundice without incompatibility.

Determinations of levels of hemoglobin, serum bilirubin, and reticulocyte counts in cord blood and in blood samples on the 4th day of life demonstrated that hyperbilirubinemia in the G-6-PD-deficient newborns was due to hemolysis already present at birth.
Jaundice in G-6-PD normal full-term newborns without incompatibility, which was very frequent in the population of Lesbos, cannot be attributed with certainty to increased hemolysis.

It is concluded that, as a group, G-6-PD-deficient newborns have an increased rate of hemolysis during both intrauterine and neonatal life, with a higher incidence of neonatal hyperbilirubinemia. In populations like that of Lesbos, the existence of an icterogenic factor in the population as a whole results in an even greater increase in hyperbilirubinemia in G-6-PDdeficient newborns.

\section{References and 'Notes}

1. Allison, H. G.; Askonas, B.A.; Barnicot, N.A.; Blumberg, B.S. and Krimbas, G.: Deficiency of erythrocyte glucose-6-phosphate dehydrogenase in Greek populations. Ann. hum. Genet. 26: 237 (1963).

2. BeutLer, E.: Glucose-6-phosphate dehydrogenase deficiency; in: Stanbury, WyngaArden and FredRICKson The metabolic basis of inherited diseases, pp. 1060-1089 (McGraw-Hill, NewYork/Toronto/ London 1965).

3. BREWer, G.J.; TARLov, A.R. and Kellermeyer, R.W.: The hemolytic effect of primaquine. XII. Shortened erythrocyte life span in primaquinesensitive male Negroes in the absence of drug administration. J. Lab. clin. Med. 58: 217 (1961).

4. Brown, W.R. and Boon, W.H.: Ethnic group differences in plasma bilirubin levels of full-term, healthy Singapore newborns. Pediatrics 36: 745 (1965).

5. Brown, W.R. and Boon, W.H.: Hyperbilirubinemia and kernicterus in glucose-6-phosphate dehydrogenase deficient infants in Singapore. Pediatrics 41: 1055 (1968).

6. Garson, P.E. and Fischer, H.: Glucose-6-phosphate dehydrogenase deficiency and related disorders of the pentose phosphate pathway. Amer. J.Med. 41: 744 (1966).

7. Clinical Chemist: Editorial. Recommendation on a uniform bilirubin standard. Clin. Chem. 8: 405 (1962).

8. Doxiadis, S.A.; Fessas, Pr. and Valaes, T.: Erythrocyte enzyme deficiency in unexplained kernicterus. Lancet ii: 44 (1960).

9. Doxiadis, S.A.; Fessas, Ph. and Valaes, T.: Glucose-6-phosphate dehydrogenase deficiency. A new aetiological factor of severe neonatal jaundice. Lancet $i$ : 297 (1951).

10. Doxiadis, S.A. and Valaes, T.: The problem of kernicterus in Greece. Proc. med. Soc. Athens 507 (1960). 
11. Doxradis, S.A. and Valaes, T.: The clinical picture of glucose-6-phosphate dehydrogenase deficiency in early infancy. Arch. Dis. Childh. 39: 545 (1964).

12. Doxiadis, S.A.; Valaes, T.; Karaklis, A. and Stavrakakis, D.: Risk of severe jaundice in glucose-6-phosphate dehydrogenase deficiency of the newborn. Differences in population groups. Lancet ii: 1210 (1964).

13. Fessas, Pre.; Doxiadrs, S. A. and Valaes, T.: Neonatal jaundice in glucose-6-phosphate dehydrogenase deficient infants. Brit.med.J. 11: 1359 (1962).

14. Flatz, G.; Sringam, S.; Premyothin, G.; PenbHarkkul, S.; Ketusingh, R. and Chulajata, R.: Glucose-6-phosphate dehydrogenase deficiency and neonatal jaundice. Arch. Dis. Ghildh. 38: 566 (1963).

15. Flatz, G.; Thanangkul, O.; Simaryk, S. and Manmontri, N.: Glucose-6-phosphate dehydrogenase deficiency and jaundice in newborn infants in Northern Thailand. Ann. paediat., Basel 203: 39 (1964).

16. Gross, R.T.; Sahroeder, E.A.R. and BrounSTEIN, S.A.: Energy metabolism in the erythrocytes of premature infants compared to full term newborn infants and adults. Blood 21: 755 1963).

17. Jande, J.H.; Engle, L.K. and Allen, D.W.: Oxydative hemolysis and precipitation of hemoglobin. I. Heinz body anemias as an acceleration of red cell aging. J. clin. Invest. 39: 1818 (1960).

18. Kaplan, E. and Hsu, K.S.: Determination of erythrocyte survival in newborn infants by means of $\mathrm{Gr}^{51}$ labeled erythrocytes. Pediatrics 27: 354 (1961).

19. Lathe, G.H. and Ruthven, G.R.J.: Factors affecting the rate of coupling of bilirubin and conjugated bilirubin in the Van den Bergh reaction. J.clin. Path. 11: 155 (1958).

20. Lu, T.C.; WeI, H. and Blackwell, R.Q.: Increased incidence of severe hyperbilirubinemia among newborn Chinese infants with G-6-PD deficiency. Pediatrics 37: 994 (1966).

21. Motulsky, A.G. and Campbell-Kraut, J.M.: Population genetics of glucose-6-phosphate dehydrogenase deficiency of the red cell. Proc. Conf. Genetic Polymorphisms and Geographic Variations in Diseases, p. 159 (Grune and Stratton, New York 1961).

22. O'Flynn, M.E.D. and Hsia, D.Y.Y.: Serum bilirubin levels and glucose-6-phosphate dehydrogenase deficiency in newborn American Negroes. J.Pediat. 63: 160 (1963).

23. Oskr, F.A.: The metabolism of erythrocytes and its relation to hemolytic anemias in the newborn. Pediat. Clin. N. Amer. 8: 687 (1965).

24. Panizon, F.: Erythrocyte enzyme deficiency in unexplained kernicterus. Lancet ii: 1093 (1960).

25. Panizon; F.; Mela, Gh.: La bilirubinemia nei neonatati con difetto di glucosio-6-phosphato dehydrogenasi. Pediatria 69: 422 (1961).

26. Paraskevopoulos, H. and Doxiadis, S. A.: Kernicterus without incompatibility. Proc. Greek Pediatric Soc. 18 (1955).

27. SAY, B.; OzAnd, P.; Berkel, I. and Cevik, N.: Erythrocyte glucose-6-phosphate dehydrogenase deficiency in Turkey. Acta paediat. scand. 54: 319 (1965).

28. SMith, G. and Veld.A, F.: Erythrocyte enzyme deficiency in unexplained kernicterus. Lancet $i: 1133$ (1960).

29. Szeinberg, A.; Oliver, M.; Schmidt, R.; AdAm, A. and ShebA, G.: Glucose-6-phosphate dehydrogenase deficiency and hemolytic disease of the newborn in Israel. Arch. Dis. Childh. 38: 23 (1963).

30. Tarlov, A.R.; Brewer, G.J.; Garson, P.E. and Alving, A.S.: Primaquine sensitivity: glucose-6phosphate dehydrogenase deficiency: an inborn error of metabolism of medical and biological significance. Arch. intern. Med. 109: 209 (1962).

31. Valaes, T.: Red cell enzymes and severe neonatal jaundice. Cerebral Palsy Bull. 3: 431 (1961).

32. VALAes, T.: Bilirubin and red cell metabolism in relation to neonatal jaundice. Postgrad. med.J. 45: 82 (1969).

33. Valaes, T. and Karaklis, A.: Relation of severe jaundice from G-6-PD deficiency to the general pattern of neonatal hyperbilirubinemia in the population. Presented at the IXth Ann. Meet. European Club for Pediatric Research, Gopenhagen 1967.

34. Vest, M.F. and Grieder, H.R.: Erythrocyte survival in the newborn infant as measured by chronium $^{51}$ and its relation to the postnatal serum bilirubin level. J.Pediat. 59: 194 (1961).

35. WALLER, H. D. : Über den Hämolysemechanismus bei Primaquinesensitiven Erythrocyten. Proc. Europ. Symp.Medicine Enzymology, Milano 1960, pp.219-233 (Karger, Basel/New York 1961).

36. Weatherall, D.J.: Enzyme deficiency in hemolytic disease of the newborn. Lancet $i i: 835$ (1960).

37. Wolff, J. A.; Grossman, B.H. and Paya, K. : Neonatal serum bilirubin and glucose-6-phosphate dehydrogenase. Amer. J. Dis. Childh. 113: 251 (1967).

38. Yue, P.G.K. and Strickland, M.: Glucose-6phosphate dehydrogenase deficiency and neonatal jaundice in Chinese male infants in Hong Kong. Lancet $i: 350$ (1965)

39. Zrnkнам, W.H.: Peripheral blood and bilirubin 
values in normal fullterm primaquine-sensitive Negro infants. Effect of vitamin K. Pediatrics 31: 983 (1963).

40. Most of the material of this paper was used for an essay awarded the 1st prize of a competition in memory of Professor K. Choremis.

41. The present work was made possible by a generous research grant from the Association for Aid to Crippled Children, New York. The authors grate- fully acknowledge the help and collaboration of the medical and administrative staff of the Vostanion Hospital in Lesbos and of the State Hospital in Rhodes; of the obstetricians and pediatricians of the two islands; of the technical staff of our laboratories and of Olympic Airways.

42. Request for reprints should be addressed to Dr. T.Valaes, The Aghia Sophia Children's Hospital, Athens 608 (Greece). 